\title{
Diazoxide maintenance of myocyte volume and contractility during stress: Evidence for a non-sarcolemmal $K_{\mathrm{ATP}}$ channel location
}

\author{
Angela D. Sellitto, MS, ${ }^{a}$ Sara K. Maffit, BS, ${ }^{a}$ Ashraf S. Al-Dadah, MD, ${ }^{a}$ Haixia Zhang, PhD, \\ Richard B. Schuessler, PhD, ${ }^{a}$ Colin G. Nichols, PhD, ${ }^{b}$ and Jennifer S. Lawton, MD ${ }^{\mathrm{a}}$
}

\begin{abstract}
Objective: Animal and human myocytes demonstrate significant swelling and reduced contractility during exposure to stress (metabolic inhibition, hyposmotic stress, or hyperkalemic cardioplegia), and these detrimental consequences may be inhibited by the addition of diazoxide (adenosine triphosphate-sensitive potassium channel opener) via an unknown mechanism. Both SUR1 and SUR2A subunits have been localized to the heart, and mouse sarcolemmal adenosine triphosphate-sensitive potassium channels are composed of SUR2A/Kir6.2 subunits in the ventricle and SUR1/Kir6.2 subunits in the atria. This study was performed to localize the mechanism of diazoxide by direct probing of sarcolemmal adenosine triphosphate-sensitive potassium channel current and by genetic deletion of channel subunits.
\end{abstract}

Methods: Sarcolemmal adenosine triphosphate-sensitive potassium channel current was recorded in isolated wild-type ventricular mouse myocytes during exposure to Tyrode's solution, Tyrode's $+100 \mu \mathrm{mol} / \mathrm{L}$ diazoxide, hyperkalemic cardioplegia, cardioplegia +diazoxide, cardioplegia $+100 \mu \mathrm{mol} / \mathrm{L}$ pinacidil, or metabolic inhibition using whole-cell voltage clamp ( $\mathrm{N}=7-12$ cells per group). Ventricular myocyte volume was measured from SUR1(-/-) and wild-type mice during exposure to control solution, hyperkalemic cardioplegia, or cardioplegia $+100 \mu \mathrm{mol} / \mathrm{L}$ diazoxide $(\mathrm{N}=7-10$ cells per group).

Results: Diazoxide did not increase sarcolemmal adenosine triphosphate-sensitive potassium current in wildtype myocytes, although they demonstrated significant swelling during exposure to cardioplegia that was prevented by diazoxide. SUR1(-/-) myocytes also demonstrated significant swelling during exposure to cardioplegia, but this was not altered by diazoxide.

Conclusions: Diazoxide does not open the ventricular sarcolemmal adenosine triphosphate-sensitive potassium channel but provides volume homeostasis via an SUR1-dependent pathway in mouse ventricular myocytes, supporting a mechanism of action distinct from sarcolemmal adenosine triphosphate-sensitive potassium channel activation. (J Thorac Cardiovasc Surg 2010;140:1153-9)

The adenosine triphosphate-sensitive potassium $\left(\mathrm{K}_{\mathrm{ATP}}\right)$ channel opener diazoxide (DZX) is cardioprotective and mimics ischemic preconditioning in animal models. ${ }^{1}$ We previously documented significant swelling of isolated myocytes and associated reduced contractility secondary to exposure to standard hypothermic hyperkalemic cardioplegia (CPG) solution in human and other species., ${ }^{2,3}$ These detrimental consequences were ameliorated by the addition of DZX. ${ }^{2,3}$ Because DZX is a $\mathrm{K}_{\mathrm{ATP}}$ channel

\footnotetext{
From the Division of Cardiothoracic Surgery, Department of Surgery, ${ }^{\mathrm{a}}$ and Department of Cell Biology and Physiology, ${ }^{\mathrm{b}}$ Washington University School of Medicine, St Louis, Mo.

Supported by the American Heart Association Beginning Grant in Aid 0565514Z (JSL) and the Thoracic Surgery Foundation for Research and Education Nina Starr Braunwald Career Development Award (JSL)

Disclosures: None.

Read at the 90th Annual Meeting of The American Association for Thoracic Surgery, Toronto, Ontario, Canada, May 1-5, 2010.

Received for publication April 28, 2010; revisions received July 12, 2010; accepted for publication July 16, 2010; available ahead of print Sept 1, 2010.

Address for reprints: Jennifer S. Lawton, MD, Washington University School of Medicine, 660 S. Euclid Avenue, Campus Box 8234, St Louis, MO 63110 (E-mail: lawtonj@wustl.edu).

$0022-5223 / \$ 36.00$

Copyright $(c) 2010$ by The American Association for Thoracic Surgery

doi:10.1016/j.jtcvs.2010.07.047
}

opener, we hypothesized that $\mathrm{K}_{\mathrm{ATP}}$ channels may play a role in myocyte volume homeostasis and that myocyte swelling may be one mechanism of myocardial stunning. ${ }^{4}$ Myocyte swelling and reduced contractility are also observed after exposure to hyposmotic and ischemic stress. ${ }^{4,5}$ Notably, DZX ameliorates both the structural and functional derangements secondary to all 3 stresses: hyperkalemic CPG, mild hyposmotic stress, and ischemic stress. $^{2-5}$ The addition of 5-hydroxydecanoate, a claimed mitochondrial $\mathrm{K}_{\mathrm{ATP}}\left(\mathrm{mK}_{\mathrm{ATP}}\right)$ channel blocker, or HMR 1098 , a claimed sarcolemmal $\mathrm{K}_{\mathrm{ATP}}\left(\mathrm{sK}_{\mathrm{ATP}}\right)$ channel blocker, to ischemic stress and hyperkalemic CPG did not alter the beneficial observations noted with DZX alone. ${ }^{2,4}$ The cardioprotective mechanism of DZX remains unknown.

DZX has been described as an $\mathrm{mK}_{\mathrm{ATP}}$ channel opener, with "selectivity" toward the $\mathrm{mK}_{\mathrm{ATP}}$ channel and only weak $\mathrm{sK}_{\mathrm{ATP}}$ channel activation at high doses. ${ }^{6}$ However, controversy regarding the specificity of $\mathrm{K}_{\mathrm{ATP}}$ channel openers and blockers suggests that pharmacologic manipulation of the $\mathrm{K}_{\mathrm{ATP}}$ channel, using potassium channel openers or sulfonylurea receptor (SUR) blockers, may be inadequate to definitively confirm ion flux across the $\mathrm{SK}_{\mathrm{ATP}}$ channel, ${ }^{7-9}$ and it remains unclear whether DZX provides cardioprotection 


$$
\begin{aligned}
& \text { Abbreviations and Acronyms } \\
& \begin{aligned}
& \mathrm{CPG}=\text { cardioplegia } \\
& \mathrm{DZX}=\text { diazoxide } \\
& \mathrm{K}_{\mathrm{ATP}}=\text { adenosine triphosphate-sensitive } \text { potassium } \\
& \mathrm{KO}=\text { knockout } \\
& \mathrm{MI}=\text { metabolic inhibition } \\
& \mathrm{mK}_{\mathrm{ATP}}=\text { mitochondrial } \mathrm{K}_{\mathrm{ATP}} \\
& \mathrm{NT}=\text { normal Tyrode's solution } \\
& \mathrm{sK}_{\mathrm{ATP}}=\text { sarcolemmal } \mathrm{K}_{\mathrm{ATP}} \\
& \mathrm{SUR}=\text { sulfonylurea receptor } \\
& \mathrm{WT}=\text { wild-type }
\end{aligned}
\end{aligned}
$$

via the $s K_{\text {ATP }}$ channel, the $\mathrm{mK}_{\mathrm{ATP}}$ channel, or a $\mathrm{K}_{\mathrm{ATP}}$ channel-independent mechanism.

$\mathrm{K}_{\mathrm{ATP}}$ channels are composed of a Kir inward rectifier channel-forming subunit and a sulfonylurea sensitive regulatory subunit, SUR (Figure 1). ${ }^{10}$ It is clear that $\mathrm{sK}_{\mathrm{ATP}}$ channels require both Kir6.2 and SUR2A subunits in the ventricle, but Kir6.2 and SUR1 in the atria. ${ }^{11}$ Both SUR1 and SUR2A are expressed in mouse heart, ${ }^{11,12}$ and there is evidence that SUR2 and SUR1 subtypes are both present in cultured neonatal rat ventricular myocytes. ${ }^{13}$ Mice lacking the SUR1 subunit seem to tolerate ischemia/reperfusion injury better than wild-type (WT) mice in a model of left anterior descending coronary artery ligation. ${ }^{12}$ Although there is some evidence for SUR1 subunits in the ventricle of various species, $\mathrm{K}_{\mathrm{ATP}}$ currents in mouse ventricle are unaltered in mice lacking the SUR1 subunit. ${ }^{11}$

We initially hypothesized that the mechanism of action of DZX might involve opening the $\mathrm{sK}_{\mathrm{ATP}}$ channel (SUR2A/ Kir6.2). Previous work documented a beneficial effect of $\mathrm{K}_{\mathrm{ATP}}$ channel opener DZX in ventricular myocytes that was unaltered by the pharmacologic inhibition of the $\mathrm{K}_{\mathrm{ATP}}$ channel. $^{2,4}$ The first part of this study was designed to definitively investigate the action of DZX by the direct measurement of $\mathrm{sK}_{\mathrm{ATP}}$ channel current in WT mice using whole-cell voltage clamp.

After demonstrating that $\mathrm{sK}_{\mathrm{ATP}}$ (SUR2A/Kir6.2) channel activity was not observed in ventricular myocytes from WT mice during exposure to DZX, and knowing that SUR1 subunits have been documented in ventricular tissue, ${ }^{11-13}$ we next hypothesized that DZX might act via SUR1 subunits of an alternative $\mathrm{K}_{\mathrm{ATP}}$ channel or some other channel in ventricular cells. The second part of this study was therefore designed to determine whether ventricular myocytes lacking the SUR1 subunit would be responsive to DZX during stress.

This study was designed to elucidate the location of action of DZX by the direct measurement of $\mathrm{sK}_{\mathrm{ATP}}$ channel activity (in WT mice) and by response to stress in ventricular myocytes from WT mice and mice lacking the SUR1 sub- unit. The elucidation of DZX's mechanism of action in this model will facilitate its future clinical use.

\section{MATERIALS AND METHODS \\ Myocyte Isolation}

All animal procedures were approved by the Animal Studies Committee at Washington University School of Medicine, and all animals received humane care in compliance with the "Guide to Care and Use of Laboratory Animals."

Ventricular myocytes were used for all experiments and isolated from adult mice (either WT or SUR1 knockout [KO], either sex, 6 weeks to 5 months, 25-30 g body weight) as previously described. ${ }^{14}$ Rapid cardiectomy was performed in the anesthetized $(2.5 \%$ tribromoethanol [Avertin; Sigma, St. Louis, Mo]) mouse, and the aorta was cannulated using a 28-gauge needle. The heart was attached to a Langendorff apparatus, and solution $\mathrm{A}$ was perfused through the aorta for 5 minutes. The heart was then perfused at $37^{\circ} \mathrm{C}$ for 12 minutes with solution $\mathrm{B}$. The left ventricle was removed and transferred into solution $\mathrm{C}$, where it was gently dispersed by glass pipette at room temperature. The cells were allowed to centrifuge by gravity, and serial washings were performed every 10 minutes for a 30-minute period. Cells were used in experiments within 5 hours after isolation. A typical yield of viable myocytes was $65 \%$ to $75 \%$ per mouse.

Solution A consisted of (in millimoles per liter, except as noted) $116 \mathrm{NaCl}$; $5.36 \mathrm{KCl} ; 0.97 \mathrm{Na}_{2} \mathrm{HPO}_{4} ; 1.47 \mathrm{KH}_{2} \mathrm{PO}_{4} ; 21.10$ HEPES; 11.65 glucose; 26.50 $\mu \mathrm{mol} / \mathrm{L}$ phenol red (Sigma); $3.72 \mathrm{MgCl}_{2} ; 4.40 \mathrm{NaHCO}_{3}$; essential vitamins $(100 \times, 10 \mathrm{~mL}$; GIBCO, Grand Island, NY); and amino acids $(50 \times, 20 \mathrm{~mL}$; GIBCO). Solution B consisted of solution A plus $10 \mu \mathrm{mol} / \mathrm{L} \mathrm{CaCl}_{2}$ and $1.2 \mathrm{mg} / \mathrm{mL}$ collagenase (Type 2; Worthington Biochemical Corporation, Freehold, NJ). Solution C consisted of solution A plus $5 \mathrm{mg} / \mathrm{mL}$ bovine serum albumin (Sigma), $1.25 \mathrm{mg} / \mathrm{mL}$ taurine, and $150 \mu \mathrm{mol} / \mathrm{L} \mathrm{CaCl}_{2}$.

The DZX (7-chloro-3-methyl-1,2,4-benzothiadiazine-1,1-dioxide; Sigma) dose of $100 \mu \mathrm{mol} / \mathrm{L}$ was used because it was effective in ameliorating cell swelling secondary to stress (hyperkalemic CPG, hyposmotic stress, and metabolic inhibition $[\mathrm{MI}]$ ) in previous studies. ${ }^{2-5}$ A stock solution of DZX was made by dissolving the reagent in $0.1 \%$ dimethyl sulfoxide, at which concentration dimethyl sulfoxide has no effect on cell volume. ${ }^{15}$

Cells were selected for viability using the following criteria: normal rod shape, smooth edges, sharp borders and clear striations, absence of vacuoles or blebbing, and lack of spontaneous beating. ${ }^{15}$ After isolation, acceptable myocytes were randomly assigned to a test solution group. A maximum of 2 cells were used per each animal.

\section{Electrophysiology in Wild-Type Myocytes}

After isolation, WT myocytes were placed in a recording chamber containing normal Tyrode's solution (NT). Macroscopic currents in isolated ventricular myocytes were recorded using standard whole-cell voltage-clamp recording techniques. ${ }^{16}$ Patch-clamp electrodes (1-3 M $\Omega$ when filled with electrode solution) were fabricated from soda lime glass microhematocrit tubes (Kimble 73813, Kimble Glass Co, Vineland, NJ). Electrode solution contained the following (in millimoles/liter): $140 \mathrm{KCl}, 10 \mathrm{HEPES}$, and 10 EGTA (pH 7.3-7.4). Cell capacitance and series resistance were determined using a 5- to 10-mV hyperpolarizing square pulse from a holding potential of $-70 \mathrm{mV}$ after establishment of the whole cell recording configuration. PClamp 9.2 software and DigiData 1322 (both from Molecular Devices, Sunnyvale, Calif) were used to generate command pulses and collect data. Data were filtered at $5 \mathrm{kHz}$. A 4-second ramp from -110 and $40 \mathrm{mV}$ was used to isolate and detect $\mathrm{sK}_{\mathrm{ATP}}$ channel current only. ${ }^{17}$

\section{Experimental protocol}

Isolated WT myocytes were exposed to NT for baseline measurement for 1 to 2 minutes, followed by exposure to test solution (5-10 minutes), and followed by NT for 5 to 10 minutes. Test solutions included NT ( $\mathrm{n}=8$ cells), NT $+100 \mu \mathrm{mol} / \mathrm{L}$ DZX ( $\mathrm{n}=7$ cells), hyperkalemic CPG in the form of St Thomas' solution (CPG, Plegisol, Abbott Laboratories, North 
SURx Kir6.x
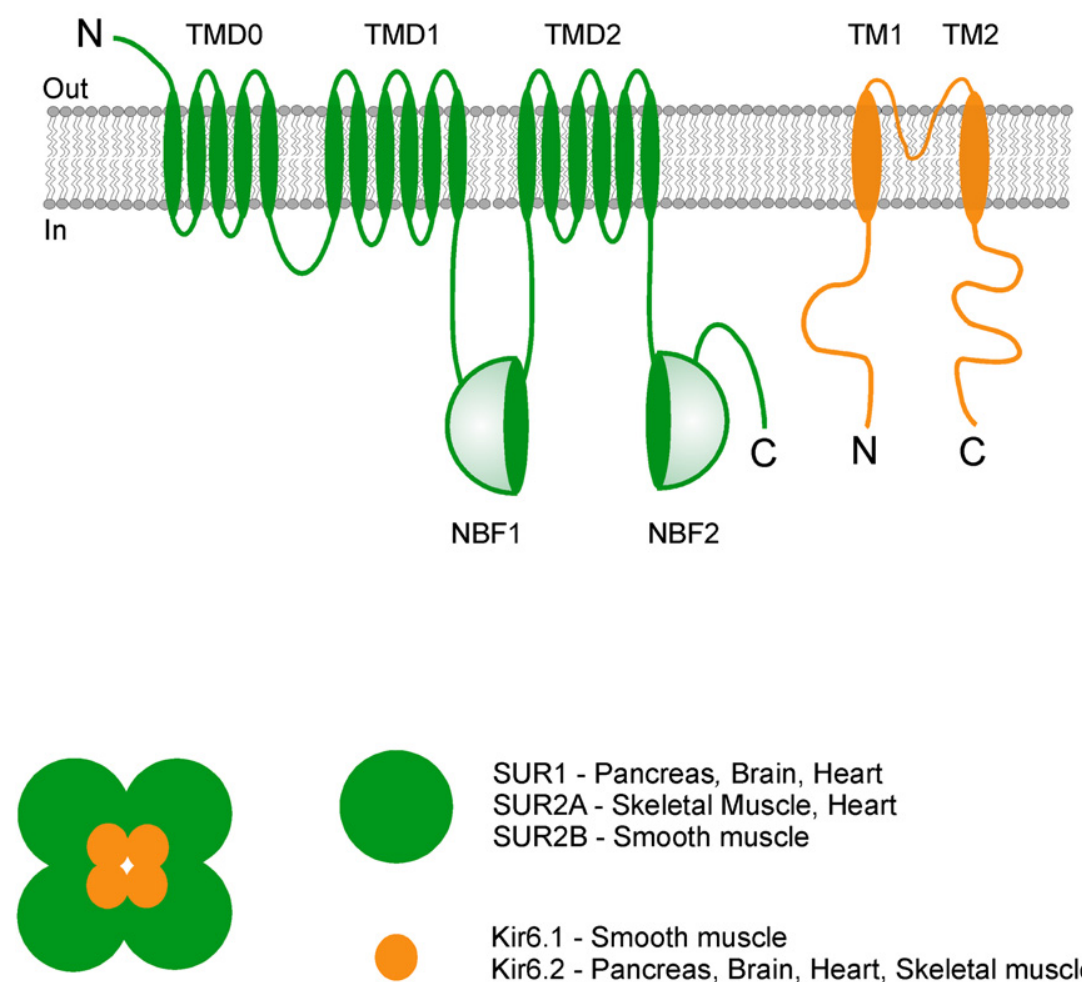

SUR1 - Pancreas, Brain, Heart

SUR2A - Skeletal Muscle, Heart

SUR2B - Smooth muscle

Kir6.1 - Smooth muscle

Kir6.2 - Pancreas, Brain, Heart, Skeletal muscle

FIGURE 1. Composition of the $\mathrm{sK}_{\mathrm{ATP}}$ channel and location of various subunits in various tissues. The channel is a functional octamer of $4 \mathrm{Kir} 6 . \mathrm{x}$ subunits (generating the channel pore) and 4 SUR subunits that generate the regulatory subunit. $T M D$, Transmembrane domain; $N B F$, nucleotide-binding fold; $M 1$, $M 2$, transmembrane helices.

Chicago, Ill) $(\mathrm{n}=11$ cells $), \mathrm{CPG}+100 \mu \mathrm{mol} / \mathrm{L}$ DZX ( $\mathrm{n}=8$ cells $), \mathrm{CPG}+$ $100 \mu \mathrm{mol} / \mathrm{L}$ pinacidil (Sigma) $(\mathrm{n}=12$ cells), and MI $(\mathrm{n}=8$ cells). NT consisted of the following (in millimoles/liter): $137 \mathrm{NaCl}, 5.4 \mathrm{KCl}, 25$ $\mathrm{NaH}_{2} \mathrm{PO}_{4}, 10$ glucose, $0.5 \mathrm{MgCl}_{2}, 5$ HEPES, and $3 \mathrm{NaHCO}_{3}(\mathrm{pH} 7.3-$ 7.4). St Thomas' solution consisted of (in millimoles/liter) $110 \mathrm{NaCl}, 10$ $\mathrm{NaHCO}_{3}, 16 \mathrm{KCl}, 32 \mathrm{MgCl}_{2}$, and $2.4 \mathrm{CaCl}_{2}$, and was equilibrated with $95 \% \mathrm{O}_{2} 5 \% \mathrm{CO}_{2}$ and titrated to correct to $\mathrm{pH}$ 7.3. MI solution consisted of (in millimoles/liter) $137 \mathrm{NaCl}, 5.4 \mathrm{KCl}, 3 \mathrm{NaHCO}_{3}, 0.16 \mathrm{NaH}_{2} \mathrm{PO}_{4}, 10$ 2-deoxyglucose, $0.5 \mathrm{MgCl}_{2}, 5 \mathrm{HEPES}, 5 \%$ oligomycin, and $3 \mathrm{NaHCO}_{3}$ $\left(\mathrm{pH}\right.$ 7.3-7.4). Isolated $\mathrm{sK}_{\mathrm{ATP}}$ channel activity and cellular capacitance were recorded during exposure to NT and compared with channel activity during test solution exposure.

MI was used as a positive control to document an increase in $\mathrm{SK}_{\mathrm{ATP}}$ channel current. Myocytes that demonstrated an increase in potassium current were subsequently exposed to glibenclamide $\left(10 \mu \mathrm{mol} / \mathrm{L}\right.$, a known $\mathrm{sK}_{\mathrm{ATP}}$ channel blocker; Sigma) to confirm that the increase in potassium current during exposure to MI was through $\mathrm{sK}_{\mathrm{ATP}}$ channels.

\section{Myocyte Volume Imaging in Wild-Type and SUR1 (-/-) Myocytes}

An aliquot of isolated myocytes was placed in a glass-bottomed chamber on an inverted microscope stage (Leitz, Wetzlar, Germany) equipped with Hoffman modulation optics (Modulation Optics, Greenvale, NY). After a 5-minute stabilization period, the chamber was perfused at a rate of 3 $\mathrm{mL} / \mathrm{min}$ with $37^{\circ} \mathrm{C} \mathrm{NT}$ (in millimoles/liter) $130 \mathrm{NaCl}, 5 \mathrm{KCl}, 2.5 \mathrm{CaCl}_{2}$, $1.2 \mathrm{MgSO}_{4}, 24 \mathrm{NaHCO}_{3}, 1.75 \mathrm{Na}_{2} \mathrm{HPO}_{4}$, and 10 glucose, buffered to a pH of 7.4 using $95 \% \mathrm{O}_{2}-5 \% \mathrm{CO}_{2}$. Chamber temperature was controlled by a waterbath system (Thermo Haake, Karlsruhe, Germany). Cell images were displayed on a video monitor using a charge-coupled device camera (KPM1U; Hitachi Denshi, Tokyo, Japan). Digital images of cells were captured at a rate of 120 frames per second using a video-frame grabber (Scion Corp, Frederick, Md) and manually traced using Scion Image software (Scion Corp). Length, width, and area were measured and recorded. To calculate cell volume, it was assumed that changes in cell width and thickness were proportional, and relative cell volume change was determined by the following formula: ${ }^{15}$

$$
\text { volume }_{t} / \text { volume }_{c}=\left(\operatorname{area}_{t} \times \text { width }_{t}\right) /\left(\operatorname{area}_{c} \times \text { width }_{c}\right)
$$

where $t$ and $c$ refer to test and control, respectively. On the basis of repeated measurements of single images and measurements of multiple images of a cell, this methodology for estimating cell volume has been shown to be reproducible with an error of less than $1 \% .^{15}$

SUR1(-/-) mice were created by removal of the 1-kbp gene segment containing both promoter and exon 1 sequences of SUR1 gene by re-mediated recombination. ${ }^{18}$ Genotype was confirmed by polymerase chain reaction analysis. ${ }^{18}$ This deletion is not lethal, and the SUR1 (-/-) mice lack pancreatic $\beta$ cell $\mathrm{K}_{\mathrm{ATP}}$ channels (SUR1/Kir6.2) and glucose-stimulated insulin secretion, and are mildly glucose intolerant. ${ }^{18}$

\section{Experimental protocol}

Myocytes were not subjected to ischemia or modified ischemia in this protocol to delineate changes caused by the stress of exposure to CPG alone. Myocytes from WT and $\mathrm{KO}$ mice were perfused with $37^{\circ} \mathrm{CNT}$ for 5 minutes to obtain baseline measurements. Any baseline changes in cell volume secondary to the isolation or imaging protocol would be evident during this period. Myocytes were then perfused for 5 minutes with test solution, followed 

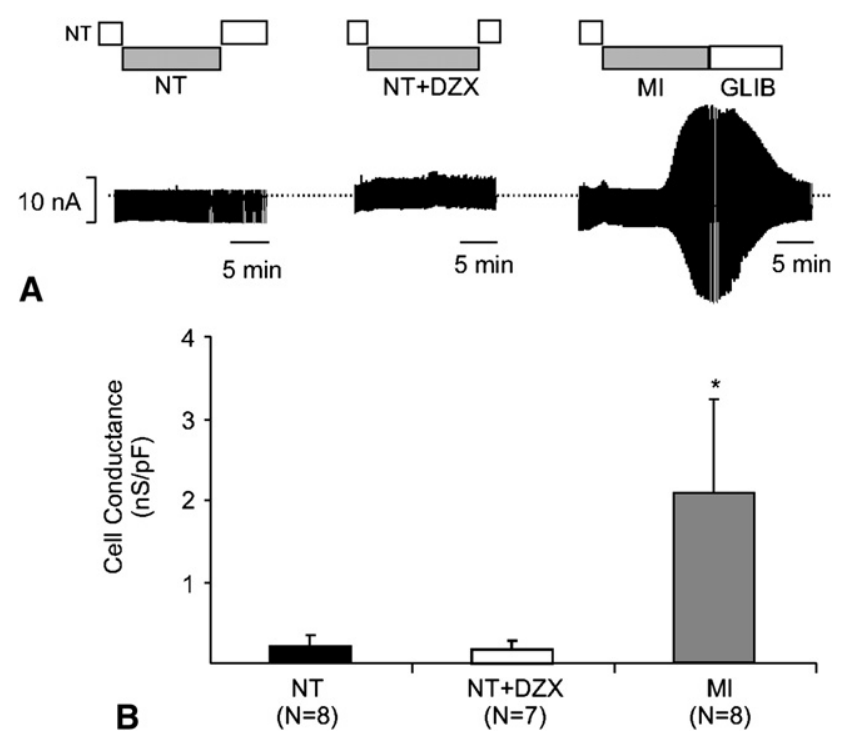

FIGURE 2. A, DZX does not elicit sarcolemmal adenosine triphosphatesensitive potassium current in WT myocytes. The y-axis represents potassium current (nA), and the x-axis represents time. WT myocytes were initially exposed to NT for baseline potassium current measurement, followed by test solution and reexposure to NT. The first graph (far left) is a representative cell exposed to NT throughout the experiment. The second graph (middle) is a representative cell exposed to NT with DZX during the test period. The addition of DZX to NT did not alter the potassium current. The third graph (far right) is a representative cell exposed to NT followed by MI. MI was associated with an increase in potassium current that was reversed by the addition of glibenclamide. B, DZX does not elicit $\mathrm{sK}_{\mathrm{ATP}}$ current in WT myocytes. Cell conductance is represented in nanoseimens/picofarads (y axis) and the test solution on the $\mathrm{x}$-axis. Test solutions included NT in addition to DZX and MI. When correcting for cell conductance, there was a significant increase in potassium current in cells exposed to $\mathrm{MI}\left({ }^{*} P=.002\right.$ vs NT). $D Z X$, Diazoxide; $M I$, metabolic inhibition; $N T$, normal Tyrode's solution; $N$, number of myocytes; GLIB, glibenclamide.

by a 5-minute reexposure period to $37^{\circ} \mathrm{C}$ NT. Test solutions included NT ( $\mathrm{n}=8$ cells for KO; $\mathrm{n}=7$ cells for WT), hyperkalemic CPG in the form of St Thomas' solution ( $\mathrm{n}=10$ cells for KO; $\mathrm{n}=7$ cells for WT), or $\mathrm{CPG}+100 \mu \mathrm{mol} / \mathrm{L}$ DZX $(\mathrm{n}=8$ cells for KO; $\mathrm{n}=7$ cells for WT). Volume measurements were made after the end of each 5 -minute period.

\section{Statistical Analysis}

Data were analyzed using SYSTAT 11 (SYSTAT Software Inc, Point Richmond, Calif). All data are presented as mean value \pm standard error of the mean, with $\mathrm{N}$ equal to the number of cells in each group. For cell volume measurements, a repeated-measures analysis of variance was used for sequential time-based measurements for each test solution against its own baseline value. By using Fisher's least significant difference test, post hoc multiple comparisons between different test groups were made separately during the test solution and reexposure periods. For electrophysiology experiments, Student $t$ test was used to compare data.

\section{RESULTS}

\section{Sarcolemmal $\mathbf{K}_{\mathrm{ATP}}$ Channel Current in Wild-Type Myocytes}

WT ventricular myocytes exposed to NT exhibited no increase in sarcolemmal adenosine triphosphate-sensitive
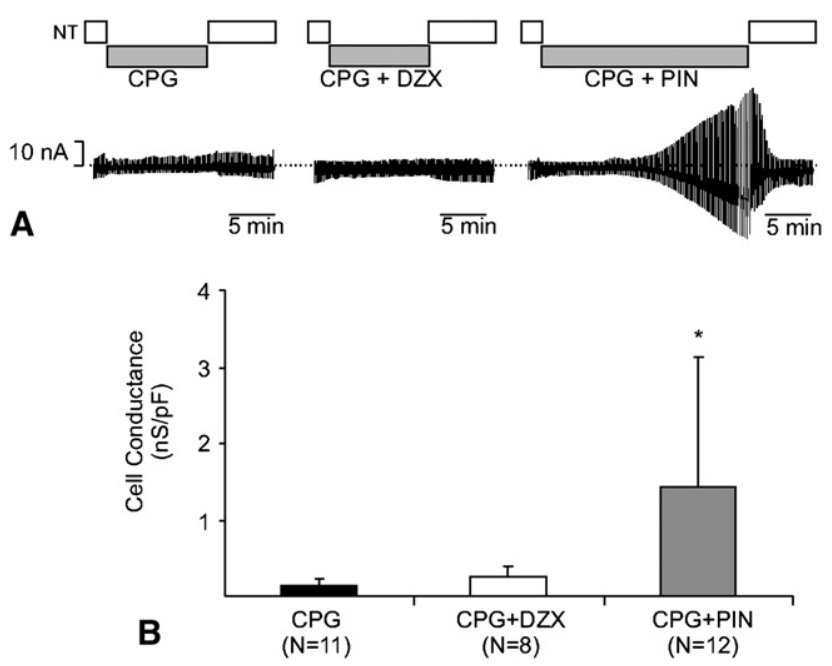

FIGURE 3. A, Pinacidil elicits an increase in adenosine triphosphatesensitive potassium current in WT cells exposed to CPG, whereas DZX does not. The $y$-axis represents potassium current (nA), and the $\mathrm{x}$-axis represents time. WT myocytes were initially exposed to NT for baseline potassium current measurement, followed by test solution and reexposure to NT. The first graph (far left) is a representative cell exposed to hyperkalemic CPG (St Thomas solution) alone during the test period. The second graph (middle) is a representative cell exposed to CPG with DZX during the test period. The third graph (far right) is a representative cell exposed to CPG with pinacidil during the test period. The addition of pinacidil to CPG induced potassium current. B, Pinacidil elicits an increase in $\mathrm{K}_{\mathrm{ATP}}$ current in WT cells exposed to CPG, whereas DZX does not. Cell conductance is represented in nanoseimens/picofarads (y-axis) and test solution on the $\mathrm{X}$ axis. Test solutions included hyperkalemic CPG (St Thomas solution), CPG with DZX, and CPG with pinacidil. When correcting for cell conductance, there was a significant increase in potassium current in cells exposed to pinacidil supplemented CPG $(* P=.025$ vs $C P G) . C P G$, Cardioplegia; $D Z X$, diazoxide; PIN, pinacidil; $N$, number of myocytes; $N T$, normal Tyrode's solution; PIN, pinacidil.

potassium current throughout the experiment (Figure 2, A), and the addition of DZX to NT was not associated with an increase in potassium current (Figure 2, A). sK $\mathrm{STTP}_{\mathrm{AT}}$ current increased significantly in WT cells exposed to MI ( $P=.002$ vs Tyrode's) (Figure $2, B)$ and was inhibited by the addition of glibenclamide (Figure 2, $A$ ).

WT myocytes exposed to CPG alone after exposure to NT exhibited no increase in $\mathrm{sK}_{\mathrm{ATP}}$ current (Figure 3, $A$ ), and the addition of DZX to CPG had no effect on the potassium current when compared with CPG alone (Figure 3,A). The addition of pinacidil in cardioplegic solution was associated with an increase in $\mathrm{SK}_{\mathrm{ATP}}$ current, which returned to baseline when cells were reexposed to NT (Figure 3, $A, B$ ). This increase in potassium current was comparable to the potassium current induced by MI.

\section{Myocyte Volume in Wild-Type and SUR1(-/-) Mice}

WT and SUR1(-/-) myocytes exposed to NT had no significant change in volume throughout the experiment 


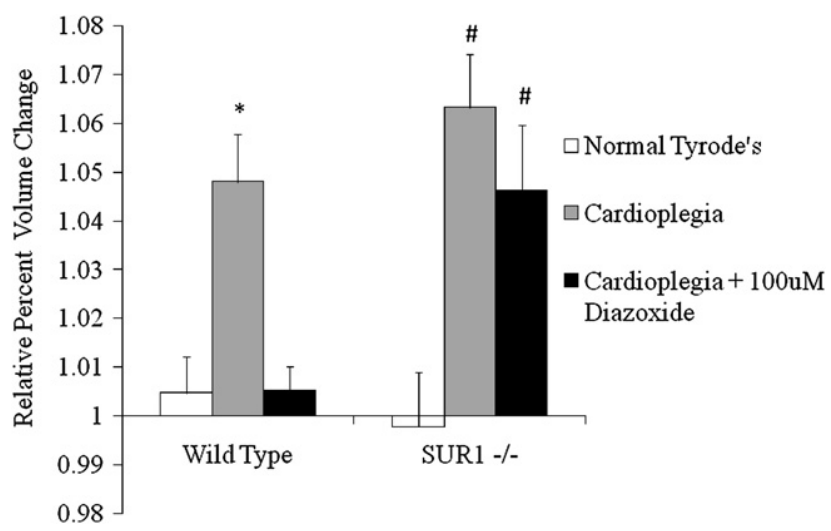

FIGURE 4. DZX requires the SUR1 subunit of the $\mathrm{K}_{\mathrm{ATP}}$ channel to maintain myocyte volume homeostasis in isolated ventricular myocytes. Myocyte volume change is represented as relative percent increase in volume for WT and SUR1(-/-) cells on the y axis. Myocytes were initially exposed to NT for 5 minutes for baseline volume measurement. Myocytes were then exposed to hyperkalemic CPG or hyperkalemic CPG $+100 \mu \mathrm{mol} / \mathrm{L}$ DZX. WT myocytes exposed to CPG significantly swelled, and this was prevented by the addition of DZX ( ${ }^{*} P<.05$ vs control and CPG + DZX). SUR1(-/-) myocytes also significantly swelled when exposed to $\mathrm{CPG}(\# P<.05$ vs control), but the addition of DZX did not prevent the swelling secondary to CPG exposure (\#P<.05 vs control). $\mathrm{N}=8$ cells for $\mathrm{KO} \mathrm{NT}, \mathrm{N}=7$ cells for $\mathrm{KO}$ WT, $\mathrm{N}=10$ cells for $\mathrm{KO}$ CPG, $\mathrm{N}=7$ cells for $\mathrm{WT}$ CPG, $\mathrm{N}=8$ cells for $\mathrm{KO}$ $\mathrm{CPG}+\mathrm{DZX}$, and $\mathrm{N}=7$ cells for $\mathrm{WT} \mathrm{CPG}+\mathrm{DZX}$.

(Figure 4). As demonstrated previously, exposure to hyperkalemic CPG resulted in significant $(P<.05$ vs control) WT myocyte swelling (Figures 4 and 5), and DZX (100 $\mu \mathrm{mol} / \mathrm{L})$ significantly ameliorated the volume change secondary to CPG $(P<.05)$. Although DZX is apparently without effect on mouse ventricular myocytes, and ventricular myocytes from SUR(-/-) animals contain normal $\mathrm{sK}_{\mathrm{ATP}}$ density, ${ }^{11}$ there was a marked loss of DZX action on cardioplegic swelling in SUR(-/-) myocytes (Figures 4 and 5). As discussed next, this result indicates that DZX is indeed ameliorating cardioplegic swelling through the SUR1 subunit, but that this is independent of $\mathrm{sK}_{\mathrm{ATP}}$ channels.

\section{DISCUSSION}

Diazoxide Is Not Associated With an Increase in sK $_{\text {ATP }}$ Channel Current in Wild-Type Ventricular Myocytes

DZX did not induce an $\mathrm{sK}_{\mathrm{ATP}}$ channel current in ventricular myocytes alone or in the presence of hyperkalemic CPG. These experiments indicate that under the observed conditions, DZX $(100 \mu \mathrm{mol} / \mathrm{L})$ does not open the $\mathrm{sK}_{\mathrm{ATP}}$ channel in isolated mouse ventricular myocytes, consistent with recent findings in mouse, ${ }^{11}$ rabbit, ${ }^{1}$ and rat ventricular myocytes. ${ }^{19}$

Previous experiments documented significant $(3.2 \%$ from baseline) myocyte swelling secondary to hyperkalemic CPG in myocytes isolated from mice lacking the Kir6.2 subunit of the $\mathrm{sK}_{\mathrm{ATP}}$ channel. ${ }^{3}$ This swelling was not altered by the addition of DZX. Together with the findings of the present study, these data could be consistent with an action of DZX on a unique ventricular $\mathrm{K}_{\mathrm{ATP}}$ channel composed of Kir6.2/SUR1. Such a composition is clearly the major composition in pancreatic, neuronal, and mouse atrial cells, ${ }^{20}$ but there is clear evidence that SUR2A, and not SUR1, is the critical SUR subunit in generation of mouse ventricular $\mathrm{K}_{\text {ATP. }}{ }^{11,21}$

\section{Both Pinacidil and Metabolic Inhibition Produce an Increase in sK $\mathrm{ATP}_{\mathrm{P}}$ Channel Current in Wild-Type Myocytes}

Pinacidil, a nonspecific $\mathrm{K}_{\mathrm{ATP}}$ channel opener, was associated with a significant increase in $\mathrm{sK}_{\mathrm{ATP}}$ channel current, consistent with the findings of previous studies. ${ }^{22} \mathrm{MI}$ is known to induce a large $\mathrm{sK}_{\mathrm{ATP}}$ channel current, and this is consistent with the results of the present study. ${ }^{23}$

\section{Mechanism of Myocyte Swelling Secondary to Stress}

In the present study, the myocyte volume derangement after exposure to hyperkalemic CPG alone was evaluated as in previous work. ${ }^{2}$ WT and SUR1(-/-) myocytes both demonstrated a significant increase in size after exposure to hyperkalemic CPG (4\%-7\% increase in size vs baseline volume). Similar volume derangements have been observed after mild hyposmotic stress (6\% increase in volume) and MI (10\% increase in volume). ${ }^{4,5}$ Each stress exposed the myocyte to a unique osmotic challenge: hyperkalemic CPG exposed the myocyte to a hyposmotic extracellular environment, hyposmotic stress exposed the myocyte to a different hyposmotic extracellular environment, and MI exposed the myocyte to a hyperosmotic intracellular environment. The $\mathrm{K}_{\mathrm{ATP}}$ channel opener DZX prevented the volume derangement in response to all 3 stresses independently. The mechanism remains unknown; however, these data suggest a role in cellular volume regulation.

\section{Maintenance of Myocyte Volume Homeostasis by Diazoxide Requires SUR1}

Myocytes from mice lacking the SUR1 gene also swelled significantly when exposed to CPG; however, DZX failed to reverse the effect. This finding indicates that DZX is in fact ameliorating cardioplegic swelling through the SUR1 subunit, but that this is independent of $\mathrm{sK}_{\mathrm{ATP}}$ channels. This raises the possibility that SUR1 is actually present in mouse ventricle, but is not required for or part of the $\mathrm{sK}_{\mathrm{ATP}}$ channel.

\section{Location of Action of Diazoxide}

The results of the present study suggest that the observed protective mechanism of DZX in isolated myocytes (maintenance of volume homeostasis and contractility during stress) is dependent on the SUR1 subunit, but is independent of the $\mathrm{sK}_{\mathrm{ATP}}$ channel. The mechanism of action may be at the mitochondrial $\left(\mathrm{mK}_{\mathrm{ATP}}\right)$ level or at a $\mathrm{K}_{\mathrm{ATP}}$ channel-independent 
BASELINE
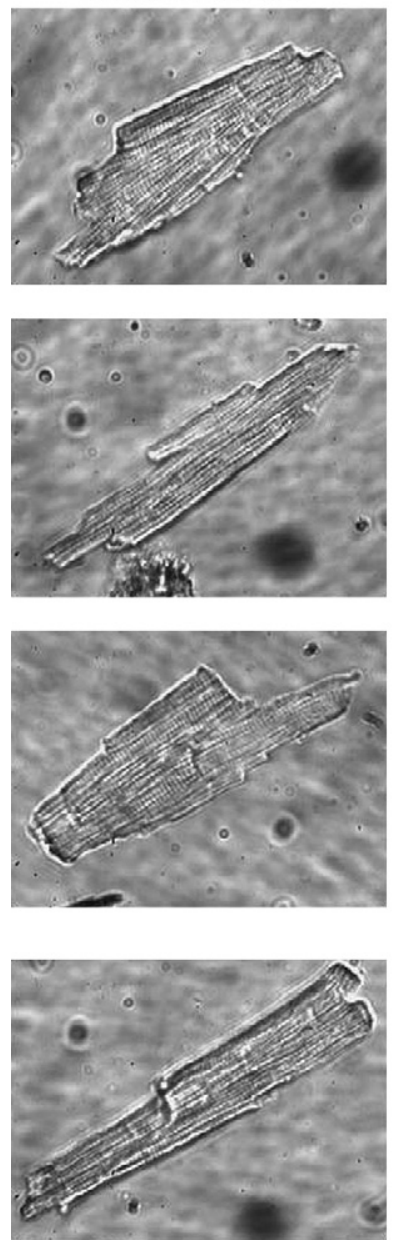

TEST
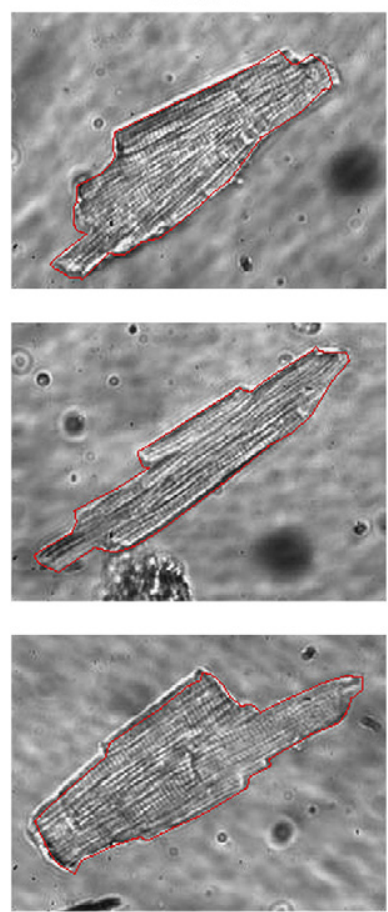

\section{SUR1 (-/-) CPG}

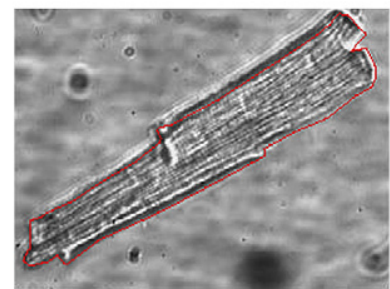

\section{WT CPG}

$\mathrm{WT} C P G+\mathrm{DZX}$

FIGURE 5. Representative isolated WT or SUR1 (-/-) myocytes at baseline volume and after exposure to test solution via inverted microscopy. Myocytes were initially exposed to NT for 5 minutes for baseline volume measurement. Myocytes were then exposed to test solution (hyperkalemic CPG or hyperkalemic CPG $+100 \mu \mathrm{mol} / \mathrm{L}$ DZX). The red line drawn on the representative test cell represents the outline of that cell's baseline volume. Significant volume increase was noted in response to CPG in the WT and SUR (-/-) cells, and this was eliminated with the addition of DZX in the WT cells only. WT, Wild-type; $C P G$, cardioplegia; $D Z X$, diazoxide.

location in the ventricle. Many investigators attribute the myocardial protection provided by $\mathrm{K}_{\mathrm{ATP}}$ channel openers to the opening of the purported $\mathrm{mK}_{\mathrm{ATP}}$ channel rather than the $\mathrm{sK}_{\mathrm{ATP}}$ channel. ${ }^{6,24,25}$ However, much of the data claimed as support for the existence of an $\mathrm{mK}_{\mathrm{ATP}}$ channel have been indirect, ${ }^{26-28}$ including by measurement of mitochondrial flavoprotein oxidation. Critics have noted that DZX inhibits succinate dehydrogenase activity, which in turn will inhibit the tricarboxylic acid cycle leading to oxidation of mitochondrial flavoproteins. ${ }^{27}$ Other evidence supported by patch clamping of the inner mitochondrial membrane documenting the presence of $\mathrm{mK}_{\mathrm{ATP}}$ channels has been criticized because of its lack of reproducibility and potential contamination by other cellular membranes. ${ }^{7,27,29}$ The determination of the structure of an $\mathrm{mK}_{\mathrm{ATP}}$ channel would thus facilitate localization of DZX's mechanism of action.
Recent studies have documented RNA expression for SUR1 in left ventricular tissue from failing human hearts. ${ }^{30}$ The elucidation of the composition of the $\mathrm{K}_{\mathrm{ATP}}$ channel specifically in humans will also increase the knowledge of the exact site of cardioprotection offered by DZX.

\section{Study Limitations}

This study investigated the action of DZX at the cellular level and in one species. This species was chosen because of the availability of a genetic knockout. Genetically tractable larger animal models are not available, and pharmacologic methods have limitations as discussed. Potassium current at the cellular level was measured to definitively observe any action of DZX at the $\mathrm{sK}_{\mathrm{ATP}}$ channel in isolation. Extrapolation to the whole organism level should therefore be taken with caution. 


\section{CONCLUSIONS}

The inverse relationship previously demonstrated between myocyte volume derangement and contractility in isolated myocytes suggested loss of myocyte volume homeostasis as a potential mechanism of myocardial stunning. ${ }^{4}$ The ability of DZX to prevent myocyte swelling and resultant contractile dysfunction secondary to 3 independent stresses in 3 species suggests that its use may be exploited for the reduction of myocardial stunning. Elucidation of the mechanism of action of DZX in the mouse at the cellular and subcellular levels will subsequently facilitate its acceptance and use at the clinical level.

\section{References}

1. Liu Y, Sato T, O'Rourke B, Marban E. Mitochondrial ATP-dependent potassium channels: novel effectors of cardioprotection? Circulation. 1998;97:2463-70.

2. Mizutani S, Al-Dadah AS, Bloch JB, Prasad SM, Diodato MD, Schuessler RB, et al. Hyperkalemic cardioplegia-induced myocyte swelling and contractile dysfunction: prevention by diazoxide. Ann Thorac Surg. 2006;81:154-9.

3. Prasad SM, Al-Dadah AS, Byrd GD, Flagg TP, Gomes J, Damiano RJ, et al. Role of the sarcolemmal adenosine triphosphate-sensitive potassium channel in hyperkalemic cardioplegia-induced myocyte swelling and reduced contractility. Ann Thorac Surg. 2006;81:148-53.

4. Al-Dadah AS, Voeller RK, Schuessler RB, Damiano RJ, Lawton JS. Maintenance of myocyte volume homeostasis during stress by diazoxide is cardioprotective. Ann Thorac Surg. 2007;84:857-62.

5. Mizutani S, Prasad SM, Sellitto AD, Schuessler RB, Damiano RJ Jr, Lawton JS. Myocyte volume and function in response to osmotic stress: observations in the presence of an adenosine triphosphate-sensitive potassium channel opener. Circulation. 2005;112(9 Suppl):I219-23.

6. Hu H, Sato T, Seharaseyon J, Liu Y, Johns DC, O’Rourke B, et al. Pharmacological and histological distinctions between molecularly defined sarcolemmal $\mathrm{K}_{\mathrm{ATP}}$ channels and native cardiac mitochondrial $\mathrm{K}_{\mathrm{ATP}}$ channels. Mol Pharm. 1999;55:1000-5.

7. Das M, Parker JE, Halestrap AP. Matrix volume measurements challenge the existence of diazoxide/glibenclamide-sensitive $\mathrm{K}_{\mathrm{ATP}}$ channels in rat mitochondria. J Physiol. 2003;547:893-902.

8. D'hahan N, Moreau C, Prost AL, Jacquet H, Alekseev AE, Terzic A. Pharmacological plasticity of cardiac ATP-sensitive potassium channels toward diazoxide revealed by ADP. Proc Natl Acad Sci. 1999;96:12162-7.

9. Grover GJ, Garlid KD. ATP-sensitive potassium channels: a review of their cardioprotective pharmacology. J Mol Cell Cardiol. 2000;32:677-95.

10. Shyng S-L, Nichols CG. Octameric stoichiometry of the $\mathrm{K}_{\mathrm{ATP}}$ channel complex. J Gen Physiol. 1997;110:655-64.

11. Flagg TP, Kurata HT, Masia R, Caputa G, Magnuson MA, Lefer DJ, et al. Differential structure of atrial and ventricular KATP: atrial KATP channels require SUR1. Circ Res. 2008;103:1458-65.

12. Elrod JW, Harrell M, Flagg TP, Gundewar S, Magnuson MA, Nichols CG, et al. Role of sulfonylurea receptor type 1 subunits of ATP-sensitive potassium channels in myocardial ischemia/reperfusion injury. Circulation. 2008;117:1405-13.

13. Yokoshiki H, Sunagawa M. Antisense oligonucleotides of sulfonylurea receptors inhibit ATP-sensitive $\mathrm{K}^{+}$channels in cultured neonatal rat ventricular cells. Pflugers Arch. 1999;437:400-8.

14. Flagg TP, Remedi MS, Masia R, Gomes J, McLerie M, Lopatin A, et al. Transgenic overexpression of SUR1 in the heart suppresses sarcolemmal KATP. J Mol Cell Cardiol. 2005;39:647-56.

15. Drewnowska K, Clemo HF, Baumgarten CM. Prevention of myocardial intracellular edema induced by St. Thomas' hospital cardioplegic solution. J Mol Cell Cardiol. 1991;23:1215-21.

16. Hamill OP, Marty A, Neher E, Sakmann B, Sigworth FJ. Improved patch-clamp techniques for high-resolution current recording from cells and cell-free membrane patches. Pflugers Arch. 1981;391:85-100.

17. Flagg TP, Charpentier F, Manning-Fox J, Remedi MS, Enkvetchakul D, Lopatin A, et al. Remodeling of excitation-contraction coupling in transgenic mice expressing ATP-insensitive sarcolemmal $\mathrm{K}_{\mathrm{ATP}}$ channels. Am J Physiol Heart Circ Physiol. 2004;286:H1361-9.

18. Shiota C, Larsson O, Shelton KD, Shiota M, Efanov AM, Hoy M, et al. Sulfonylurea receptor type 1 knock-out mice have intact feeding-stimulated insulin secretion despite marked impairment in their response to glucose. $J$ Biol Chem 2002;277:37176-83

19. Garlid KD, Paucek P, Yarov-Yarovoy V, Murray HN, Darbenzio RB, D'Alonzo AJ. Cardioprotective effect of diazoxide and its interaction with mitochondrial ATP-sensitive K channels: possible mechanism of cardioprotection. Circ Res. 1997;81:1072-82.

20. Nichols CG. $\mathrm{K}_{\mathrm{ATP}}$ channels as molecular sensors of cellular metabolism. Nature. 2006;440:470-6.

21. Chutkow WA, Pu J, Wheeler MT, Wada T, Makielski JC, Burant CF, et al. Episodic coronary artery vasospasm and hypertension develop in the absence of Sur2 K(ATP) channels. J Clin Invest. 2002;110:203-8.

22. Arena JP, Kass RS. Enhancement in potassium-sensitive current in heart cells by pinacidil: Evidence for the modulation of the ATP-sensitive potassium channel. Circ Res. 1989;65:436-45.

23. Nichols CG, Ripol C, Lederer WJ. ATP-sensitive potassium channel modulation of the guinea pig ventricular action potential and contraction. Circ Res. 1991;68 280-7.

24. Toyoda Y, Levitsky S, McCully JD. Opening of mitochondrial ATP-sensitive potassium channels enhances cardioplegic protection. Ann Thorac Surg. 2001;71 1281-8.

25. Sato T, Sasaki N, Seharaseyon J, O'Rourke B, Marban E. Selective pharmacological agents implicate mitochondrial but not sarcolemmal $\mathrm{K}_{\mathrm{ATP}}$ channels in ischemic cardioprotection. Circulation. 2000;101:2418-23.

26. Hanley PJ, Mickel M, Loffler M, Brandt U, Daut J. $\mathrm{K}_{\mathrm{ATP}}$ channel-independen targets of diazoxide and 5-hydroxydecanoate in the heart. J Physiol. 2002 542.3:735-41.

27. Lim KH, Javadov SA, Das M, Clarke SJ, Suleiman M, Halestrap AP. The effects of ischaemic preconditioning, diazoxide and 5-hydroxydecanoate on rat heart mitochondrial volume and respiration. J Physiol. 2002. 545.3:961-74.

28. Rainbow RD, Lodwick D, Hudman D, Davies NW, Norman RI, Standen NB SUR2A C-terminal fragments reduce $\mathrm{K}_{\mathrm{ATP}}$ currents and ischaemic tolerance of rat cardiac myocytes. $J$ Physiol. 2004. 557.3:785-94.

29. Sorgato MC, Keller BU, Stuhmer W. Patch-clamping of the inner mitochondria membrane reveals a voltage-dependent ion channel. Nature. 1987;330:498-500.

30. Soltysinska E, Olesen SP, Christ T, Wetter E, Varro A, Grunnet M, et al. Transmural expression of ion channels and transporters in human nondiseased and end-stage failing hearts. Pflugers Arch. 2009;459:11-23.

\section{Discussion}

Dr Friedhelm Beyersdorf (Freiburg, Germany). Swelling of cardiomyocytes is an important aspect of ischemia-reperfusion injury of the heart that leads to impaired myocardial function. You simulate ischemia in your experiments by MI using a specific solution. I have 2 questions for you:

First, you showed that a current in the ATP-sensitive potassium channels is not induced by CPG but by MI. However, both conditions lead to cardiomyocyte swelling. In contrast, again, only swelling caused by MI is prevented by DZX. Could you comment on possible differences between these 2 experimental conditions?

Ms Sellitto. The hyperkalemic CPG is more of a hypo-osmotic stress as opposed to the inhibition of metabolism. Possibly, because it's a different mechanism of action in the stresses, that would be the difference in the activity of the sKATP channel.

Dr Beyersdorf. Second, Elrod and coworkers demonstrated in an article in Circulation in 2008 that SUR1 KO mice are protected against ischemia. Their experiments showed reduced infarct size and preserved function after a surgical ligation of the left coronary artery. Could you comment on a positive correlation between your and their results?

Ms Sellitto. The SUR1 unit in the mouse model has been shown to have heterozygotes found predominantly in the atria and not so much in the ventricle. But in humans, SUR1 is more homogeneous, so DZX could have an effect in preventing damage caused by ischemia in the human heart. 